\title{
Bio-Economy Contribution to Circular Economy
}

\author{
Sara Corrado and Serenella Sala
}

\begin{abstract}
European policies are advocating a transition toward "bio-economy", an economy aiming at reducing the dependence from fossil-based resources, limiting greenhouse gas emissions and environmental impacts, safeguarding food security and ensuring a sustainable economic growth. Besides, circular economy policies are aiming at closing the loop of resources as much as possible. The application of circular economy principles to bio-economy could represent a valuable contribution to bio-economy performance optimisation. The present paper investigates the contribution of bio-economy to circular economy. It proposes a conceptual framework to assess the potential for circularity for bio-waste and related by-products and it puts forward some considerations on the application of this framework to food waste. However, both bio-economy and circular economy may imply environmental burdens if an integrated assessment encompassing all life cycle stages of production and consumption is missing. Hence, adopting life cycle assessment is crucial to unveil trade-offs and ensuring identifying the best options for bio-economy and circular economy implementation.
\end{abstract}

\section{Introduction}

Natural resources provided by the Earth, both biotic and abiotic (i.e. raw materials, energy, water, air, land and soil as well as biodiversity and ecosystems) represent crucial economy and life-support elements for human societies worldwide. Indeed, natural resources are a building block in the supply chain, thus pushing the economic growth, and providing global functions, as in climate regulation. However, in a globalised world where population is in continuous expansion and the demand for finite resources continues to increase, the current production and consumption patterns in developed and developing countries are generating concerns about their

\footnotetext{
S. Corrado $\cdot$ S. Sala $(\square)$

European Commission, Joint Research Centre, Directorate D-Sustainable Resources,

Bio-Economy Unit, via Enrico Fermi 2749, 21027 I-Ispra, VA, Italy

e-mail: serenella.sala@ec.europa.eu

(C) The Author(s) 2018

E. Benetto et al. (eds.), Designing Sustainable Technologies,

Products and Policies, https://doi.org/10.1007/978-3-319-66981-6_6
} 
sustainability, with particular regard to the potential repercussion on the environment and climate. On such a background, a transition toward bio-based economy, called "bio-economy", represents an opportunity to comprehensively address inter-connected societal challenges such as food security, natural resource scarcity, fossil resource dependence and climate change, while achieving sustainable economic growth [1, 2]. However, not only fossil-based products carry an environmental burden, but also bio-based ones. Furthermore, the use of bio-based resources may raise issues on land competition for food production. Hence, to be effective, bio-economy strategies should be founded on resource efficiency and eco-innovation principles [3].

The concept of circular economy - a system in which the final disposal of waste and by-products is minimised by promoting their reuse and valorisation - can be successfully applied to bio-based production chains. Recent research developments, indeed, have highlighted several options for the conversion of bio-waste and bio-based by-products into either bioenergy, biofuels or valuable secondary raw materials [4]. Bio-based waste, indeed, represents a considerable amount of material at the global level, in the order of magnitude of gigatonnes per year [5]. The bio-economy contribution to circular economy may arise from very different typologies of bio-based products, such as wood, food, fibres, leathers and rubbers. Moreover, each step in the supply chain of bio-based products may provide waste or by-products with different characteristics, which can be valorised in various ways [2].

The present paper proposes a framework which may unveil the potential for circularity of bio-waste and bio-based by-products, coherently with the European legislative framework for waste management [6]. Furthermore, some considerations on the application of such framework to food waste and by-products, taken as a case-study are reported. Firstly, strengths and weaknesses of existing data sources and estimations approaches for food waste and by-products accounting are highlighted. Then, an overview of the options for valorisation for food waste and by-products is presented. Finally, the challenges of optimising the use of Life Cycle Assessment (LCA) when assessing the environmental performance of bio-economy value chains are discussed.

\section{Valorisation of Bio-Waste and Bio-Based By-Products}

In the European context, bio-economy is considered an important area of research, whose potential has still to be further disclosed. At present, the production of bio-materials and bioenergy is using about $36 \%$ of the biomass in Europe. However, further investigations are required to evaluate the potential availability of additional biomass, currently unused, without compromising the positive effects that biomass not removed from the field may have on soil fertility [7]. In this context, the European bio-economy sector is growing, showing a $7 \%$ increase in the turnover between 2008 and 2014. Particularly, some bio-economy branches 
increased faster than others and the highest turnover rise occurred in the manufacturing of liquid biofuels $(+25 \%)$, the production of bio-based chemicals, pharmaceuticals, plastics and rubber $(+22 \%)$, and in the forestry sector $(+21 \%)$ [2]. Furthermore, biofuels use is estimated to increase and cover between $27 \%$ and $48 \%$ of road transport fuel need in 2030 [8], whereas the demand for bioplastics, currently representing $1 \%$ of the total plastic used in Europe, is expected to increase by $50 \%$ in the period 2016-2021 [9].

Nowadays, the use of bio-waste and bio-based residues in bio-refineries is still a niche. Indeed, despite bio-waste and bio-based residues are potential sources of several high-values compounds [15], technical and non-technical barriers, such as uncertainty on the quality of materials and limited experiences at the industrial scale, are currently affecting the diffusion of their cascading use [10]. Therefore, further investigations on the practicability of valorisation strategies based on a holistic perspective are needed to foster the contribution of bio-economy to circular economy.

\section{Assessing the Potential for Circularity: The Overall Conceptual Framework and Application to Food Waste}

In order to assess the potential for circularity of bio-waste and bio-based by-products, a conceptual framework has been defined. It aims to guide in the identification of most preferable valorisation options for bio-based waste and by-products streams, as defined within the European legislation on waste [6] (Fig. 1). Therefore, it can be applied for either the identification of valorisation routes for material streams commonly disposed or the investigation of more valuable options for material flows, which are already somehow valorised.

The proposed framework, for which an example of application to food waste is reported in Fig. 2, combines the principles of the European waste hierarchy [6] and the European circular economy action plan for biomass and bio-based products [11], which promotes cascading use of renewable resource, with several reuse and recycling cycles. The underlying and key principle for defining the hierarchy of preferred actions is the minimisation of the dissipative use of high-value resources and the maximisation of the cascading use of bio-materials, meaning that reused bio-materials or the residues from the extraction of high values compounds may be reused for other purposes, e.g. animal feeding. Coherently with the European Waste Framework Directive [6], the proposed logical framework considers that a departure from the "standard" hierarchy may be justified according to the environmental preferability criterion, evaluated through a life cycle thinking approach. Other identified elements, which may limit the applicability of a certain valorisation route, are technical feasibility, economical profitability and legislation compliance.

Waste prevention should, in principle, be the preferred option. However, this might not be applicable, e.g. in case of certain by-products unavoidably delivered by a transformation process, such as bones and peels separated from the edible 
Definitions according to the European Waste Framework Directive [6]:

- waste: any substance or object which the holder discards or intends or is required to discard;

- bio-waste: biodegradable garden and park waste, food and kitchen waste from households, restaurants, caterers and retail premises and comparable waste from food processing plants;

- by product: substance or object, resulting from a production process, the primary aim of which is not the production of that item, may be regarded as not being waste referred to in point (1) of Article 3 but as being a by-product only if the following conditions are met:

(a) further use of the substance or object is certain;

(b) the substance or object can be used directly without any further processing other than normal industrial practice;

(c) the substance or object is produced as an integral part of a production process; and

(d) further use is lawful, i.e. the substance or object fulfils all relevant product, environmental and health protection requirements for the specific use and will not lead to overall adverse environmental or human health impacts.

Fig. 1 Definitions reported in the European Waste Framework Directive [6]

fractions of food or sawdust generated during wood transformation. The second option, the re-use, implies that the material can be utilised for the same purpose for which it was initially conceived. It applies, for example, to the harder discarded fractions of vegetables, which may be not suitable to be eaten directly, but can be used in the other preparations, such as soups. Bio-waste and by-products allow a wide range of recycling options, and their preferability strongly depends on the material characteristics, e.g. homogeneity and composition. Lignocellulosic biomass, for example, is composed mainly by the polymers cellulose, hemicellulose and lignin and the specific content of each of them may influence the preferable option for valorisation [12]. Furthermore, the extraction of high-value compounds is practicable when a homogeneous material stream is available, whereas it is hardly feasible in case of heterogeneous streams. Among the less preferable recycling options, anaerobic digestion was considered better than composting, because it allows a less dissipative use of the bio-based resources, recycling nutrients and producing methane at the same time. It has to be noted that the hierarchy could be subjected to modifications, according to specific sustainability priorities. For example, the maximisation of the uses for sustaining the food system may imply giving preference to the use of food waste as animal feed, rather than to be exploited as basis for bio-based materials.

Considering Fig. 2, "practicable" implies that the option is environmentally preferable, technically feasible, economically profitable and compliant to 


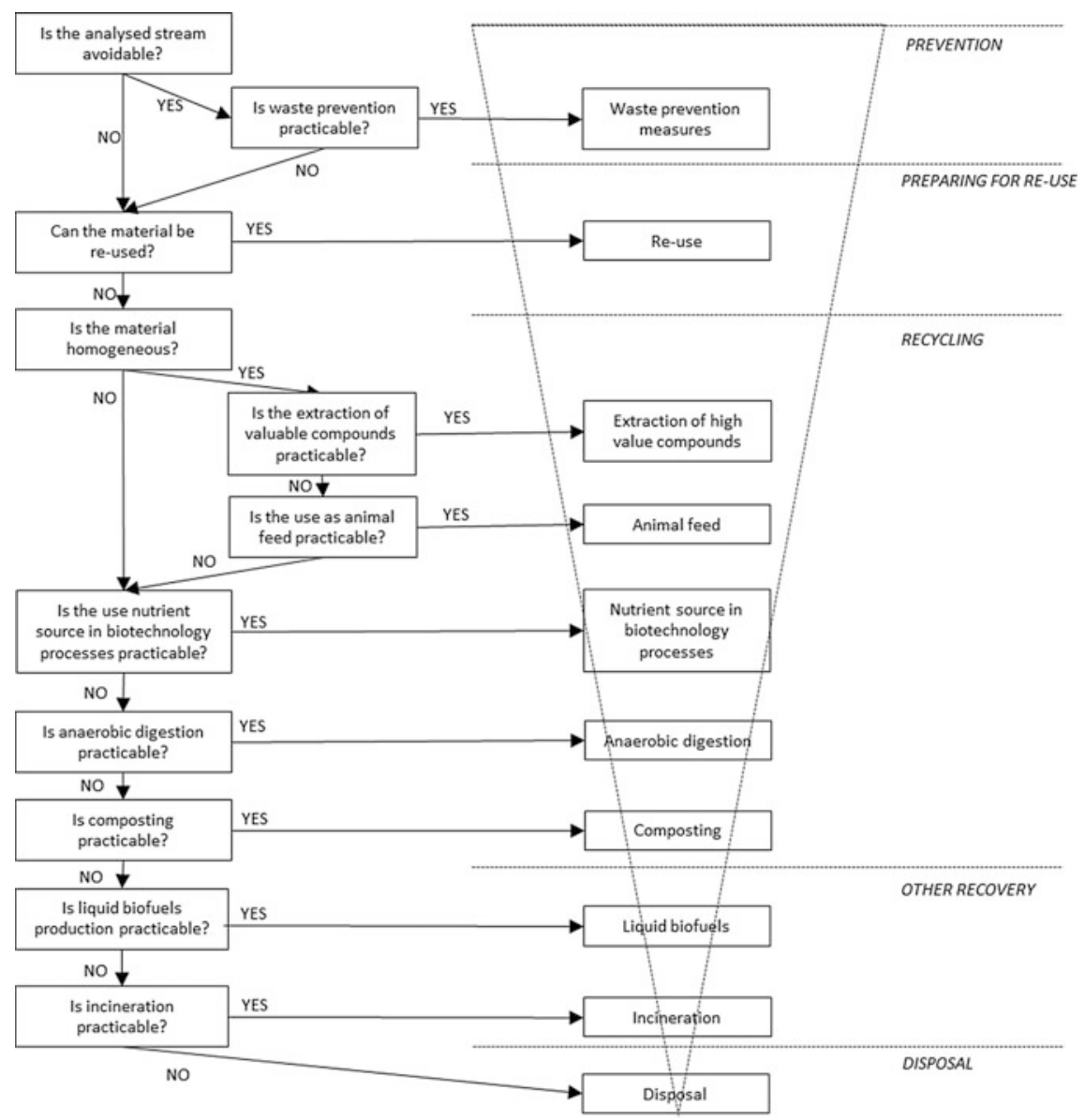

Fig. 2 Conceptual framework to identify the most valuable options for bio-waste and bio-based by-products valorisation, applied to food waste

legislation. The pyramid on the right side of the figure reports the coherence with the waste management hierarchy proposed by the European Waste Framework Directive [6].

\section{Considerations on Food Waste Valorisation from a Circular Economy Perspective}

The United Nations Food and Agriculture Organization (FAO) estimated that globally about one third of the food produced for human consumption is wasted along the supply chain [13]. In Europe, biowaste generated in households is often 
mixed with other waste [14]. However, food waste has generally a moisture content such that makes it unsuitable for incineration or thermal treatment and its presence in landfills may raise environmental concerns due to the production of leachate and methane emissions [15]. Therefore, this huge amount of bio-based materials represents a considerable potential contribution of bio-economy to circular-economy, which not only may optimise resources use, but also help facing the problem of food waste management.

\subsection{Food Waste Generation Accounting}

Being aware of the extent and the type of the waste and by-products streams is the first step towards the identification of valuable valorisation pathways for bio-based materials in general, including food waste [11]. Food waste and by-products generation encompasses all the stages of the food supply chain, from primary production to consumption. Therefore the adoption of a life cycle thinking (LCT) approach for supporting the accounting is advisable to fully capture the potentialities of food waste and by-products valorisation.

Currently, waste generation has been investigated on different geographical scales and breakdowns of the food supply chain (Fig. 3). Besides its relevance for addressing the type of food waste accounting, the matrix in Fig. 3 is also useful for the definition of specific interventions. For example, data on food waste for a specific commodity group at national/regional level may allow depicting tailored scenarios of food waste valorisation.

Results of the studies may differ due to various elements, such data sources, quantification methods, food waste definitions, system boundaries. The selection of the waste flows accounted may be a critical element, influenced by food waste definition and data sources considered. In the study by FAO on global food waste generation [13], for example, only the edible fractions of food are accounted, whereas inedible parts such as bones and fruit peels are excluded. Another criticality may be the inhomogeneity and the uncertainty of statistical data, which may limit the comparability of statistical data provided by different countires $[13,16]$.

These criticalities highlight the need of an accurate understanding of the underlying assumptions on the quantification approaches, in the interpretation of existing studies [17].

\subsection{Valorisation of Food Waste, Possible Options}

The rapidly growing attention for the circular use of bio-based resources has led to the realisation of several studies exploring potential for circularity for food waste and by-products. Not all the analysed solutions are currently developed at the industrial scale application [18]. 


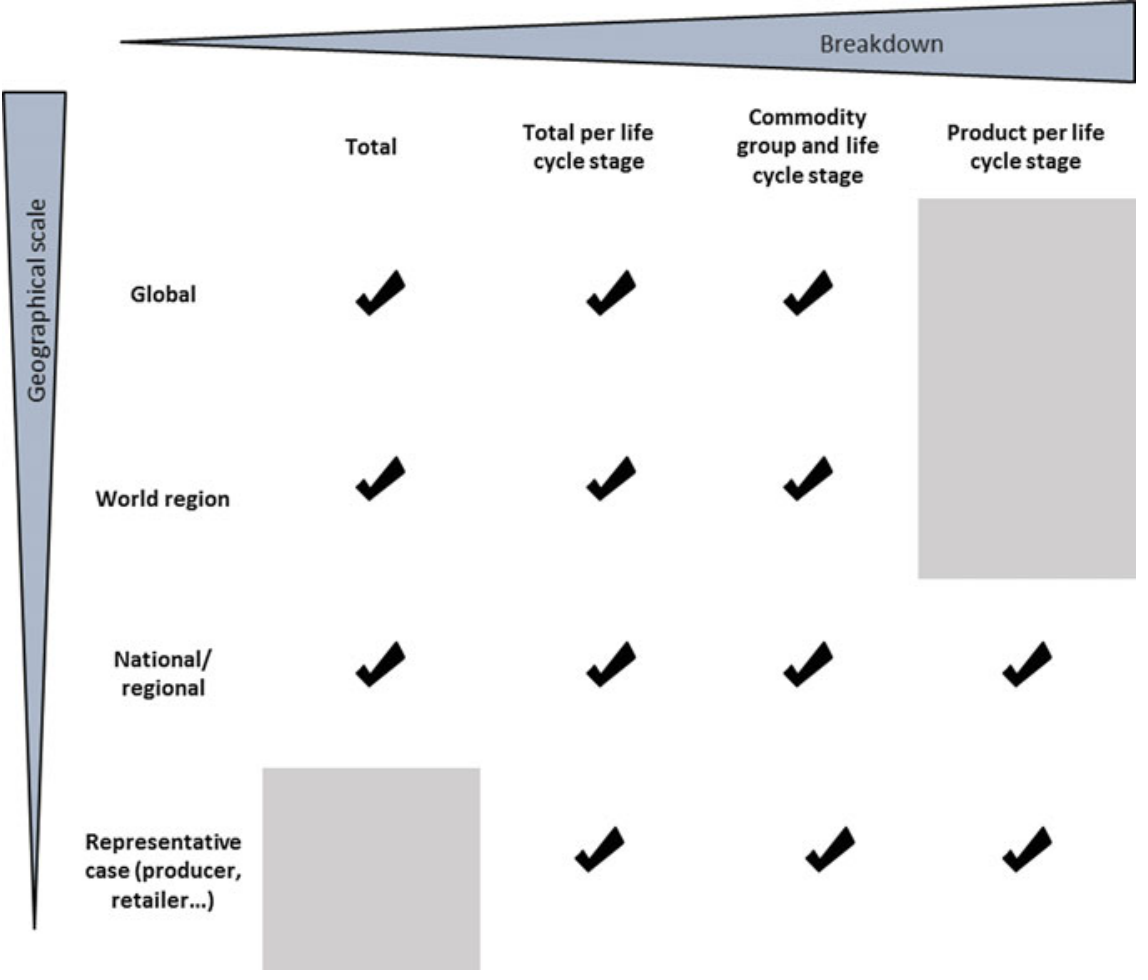

Fig. 3 Combination of geographical scale and breakdown of life cycle stages in the existing studies on food waste accounting. The checks indicate existing combination, whereas grey cells indicate fields not yet investigated

Several studies have highlighted that, being easily accessible and collected under controlled conditions, food waste and by-products from processing has homogeneous features, which give it a noteworthy potential for the extraction of high-value chemicals and for the direct valorisation as feed. Each stream of materials from processing may have in principle various routes for valorisation. However, currently the main research focus is on material flows from fruit and vegetables as source of antioxidants, fibers, phenols, polyphenols and carotenoids and waste from meat and dairy industries, vinasse, distiller's grains with solubles, press cake, fish silage, containing a large amount of recoverable proteins [15, 19].

On the contrary, the variable composition of food waste streams generated at the consumption stage, limits the possibility of extracting systematically specific molecules [18]. However, both processing waste and food waste generated at the consumption stage can be used either as nutrient sources in biotechnological processes [5] or for biofuels production [20,21]. In the last years, indeed, the interest for the production of biological metabolites to be used as biodegradable and renewable substitutes for fossil-based products, such as lactic acid and succinic 
acid, is growing fast [5, 18]. Furthermore, the valorisation of food waste for the production of bioethanol, biogas, hydrogen and biodiesel has attracted increasing attention [20].

\subsection{LCA Applied to Bio-Economy Value Chains: Future Challenges}

The assessment of the environmental preferability of the different pathways is one of the pillars of the proposed conceptual framework. On such purpose, the use of LCA, based on LCT approach, has had large diffusion both in the research and in the legislative fields. LCA, indeed, has been widely used to compare different waste management and treatment options [22, 23] and to assess the environmental performance of various bio-economy value chains [24, 25]. Furthermore, LCT is at the core of the European policies on waste management [6] to support the identification of the most environmentally sound options. One of the main advantages of this approach is the accounting of the so-called burden shifting, namely the transfer of environmental impacts between environmental compartments or supply chain stages, which may happen when pushing for resource efficiency. However, despite LCA broad acceptance and diffusion, past experiences have highlighted some shortcomings, which may limit a clear quantitative understanding of the environmental aspects of bio-economy value chains [25]. These shortcomings encompass both the product system modelling and the impact assessment side.

As mentioned previously, the interest for the valorisation of food waste and by-products as a resource is quite recent, therefore inventory data on innovative recovery processes are currently lacking. Besides, when considering circular system, setting the system boundaries may not be straightforward, influencing considerably the results of the study [26, 27]. Allocation of impacts can be another issue when dealing with food waste valorisation. Indeed, the production of food waste or by-product is, per definition, not the first target of the food system. Therefore, all the steps of the food supply chain, from primary production to consumption, can be considered multi-functional processes delivering food and food waste or by-products. The approach used to partition the impacts between co-products, namely, e.g., system expansion, bio-physical allocation or economic allocation, can importantly influence the LCA results and consequent considerations on food waste [28], limiting, therefore, their comparability [25]. Furthermore, if allocation of the impacts is performed, the allocation criteria can influence importantly the environmental performance of a bio-based product. For example, a by-product, which is commonly disposed has no economic value, whereas if it starts to be valorised as resource it would probably acquire economic value. If economic allocation is performed, the environmental burden of the by-product will increase together with its commercial value, with the potential risk of reaching or overcoming the environmental impacts of the virgin material, which is supposed to 
substitute. On the contrary, bio-physical allocation may attribute to the by-product a considerable burden of the production process, above all when a huge amount of by-product is delivered.

Concerning the impact assessment, Cristobal and colleagues [25] noted that it is a common practice to consider only a narrow number of impact categories, affecting the comprehensiveness of the results. Besides, some impact categories are based on weak calculations models, which limit their applicability. Furthermore, impact categories traditionally considered in LCA are often not enough to capture the environmental pressures exerted by food waste generation [26]. The impacts on biotic resources, for example, are generally not investigated in LCA [29]. Other relevant impact categories are still under refinement for being comprehensive in addressing issues such soil quality, biodiversity, water scarcity. All these aspects are crucial when accounting for the impacts of food waste or when comparing the environmental performance of bio-based and fossil-based products.

\section{Conclusions}

Applying circular economy principles to bio-economy represents a valuable opportunity for our society, which is called to cope with complex and important challenges, such as food security, competition for natural resources, fossil resources dependence and climate change.

A broad range of options exists for valorising bio-based waste and by-products, including already accomplished and innovative solutions, and the present paper introduced a conceptual framework to support the identification of the most valuable ones. The application of such framework is not straightforward, reflecting the complexity of multi-criteria decision-making processes and of the biological systems to which it is applied.

The main elements of the framework have been briefly introduced and discussed in relation to a specific type of bio-based material: food waste and related by-products. The accounting of food waste should be based on LCT, encompassing all the potential sources of food waste within the supply chain. Existing estimations showed some shortcomings mainly due to lack of data, uncertainties and data inhomogeneity, therefore their interpretation requires a deep knowledge of the underlying assumptions. The exploration of valorisation routes for food waste and bio-based by-products have raised considerable interests in the last years in the research field, however, part of the innovative solutions need to be further investigated, assessing their applicability at the industrial scale. Finally, LCA has shown great potentialities in supporting the assessment of the most preferable environmental options for food waste management, however still some efforts are needed to improve the comprehensiveness and robustness of LCA applied to bio-based and circular systems. 
Future industrial developments focused on valorisation of food waste should be based on robust accounting of available quantities, analysis of techno-economic potential coupled with life cycle based environmental assessment of benefits and burdens.

\section{References}

1. European Commission (EC), Innovating for Sustainable Growth: A Bioeconomy for Europe Communication from the Commission, COM (2012) 60.

2. Ronzon T, Lusser M, Klinkenberg M (ed.), Landa L, Sanchez Lopez J (ed.), M'Barek R, Hadjamu G (ed.), Belward A (ed.), Camia A (ed.), Giuntoli J, Cristobal J, Parisi C, Ferrari E, Marelli L, Torres de Matos C, Gomez Barbero M, Rodriguez Cerezo E, Bioeconomy Report 2016. JRC Scientific and Policy Report, 2017.

3. Mahro B, Timm M, Potential of biowaste from the food industry as a biomass resource, Engineering in Life Science, Vol. 7, No. 5, 2007, pp. 457-468.

4. Mohan S.V, Nikhil G.N, Chiranjeevi P, Reddy C.N, Rohit M.V, Kumar A.N, Sarkar O, Waste biorefinery models towards sustainable circular bioeconomy: critical review and future perspectives, Bioresource technology, Vol. 215, 2016, pp. 2-12.

5. Pleissner D, Qi Q, Gao C, Rivero C.P, Webb C, Lin C.S.K, Venus J, Valorization of organic residues for the production of added value chemicals: a contribution to the bio-based economy, Biochemical Engineering Journal, Vol. 116, 2016, pp. 3-16.

6. European Parliament, Directive 2008/98/EC of the European Parliament and of the Council of 19 November 2008 on waste and repealing certain Directives, DIRECTIVE 2008/98/EC.

7. Ronzon T, Santini F, M'Barek R, The Bioeconomy in the European Union in numbers - Facts and figures on biomass, turnover and employment, European Commission, Joint Research Centre, Institute for Prospective Technological Studies, Spain, 2015.

8. European Commission (EC), Biofuels in the European Union - A vision for 2030 and beyond, 2006.

9. European Bioplastics, Nova Institute, Bioplastics market data, 2016.

10. Ladu L, Quitzow R, Bio-Based Economy: Policy Framework and Foresight Thinking, Springer International Publishing, 2017.

11. European Commission (EC), Closing the loop - An EU action plan for the Circular Economy, COM (2015) 0614.

12. Isikgor F.H, Becer C.R, Lignocellulosic biomass: a sustainable platform for the production of bio-based chemicals and polymers. Polymer Chemistry, Vol 6 (25), 20015, pp. 4497-4559.

13. Food and Agriculture Organization of the United Nations (FAO), Global food losses and food waste - Extent, causes and prevention, 2011.

14. European Commission (EC), Measuring progress towards circular economy in the European Union - Key indicators for a monitoring framework, SWD (2018) 17 final.

15. Mirabella N, Castellani V, Sala S, Current options for the valorization of food manufacturing waste: a review. Journal of Cleaner Production, Vol. 65, 2014, pp. 28-41.

16. Monier V, Mudgal S, Escalon V, O'Connor C, Gibon T, Anderson G, Morton G, Preparatory study on food waste across EU 27, Report for the European Commission [DG ENVDirectorate C], 2010.

17. Tostivint C, Östergren K, Quested T, Soethoudt J.M, Stenmarck A, Svanes E, O'Connor C, Food waste quantification manual to monitor food waste amounts and progression, 2016.

18. Girotto F, Alibardi L, Cossu R, Food waste generation and industrial uses: a review, Waste Management, Vol. 45, 2015, pp. 32-41.

19. Tuck C, Pérez E, Horváth I.T, Sheldon R.A, Poliakoff M, Valorization of Biomass: Deriving More Value from Waste, Science, Vol. 337, 2012, pp. 695-699. 
20. Kiran E.U, Trzcinski A. P, Ng W.J, Liu Y., Bioconversion of food waste to energy: a review, Fuel, 2014, Vol. 134, 2014, pp. 389-399.

21. Pham T. P. T, Kaushik R, Parshetti G. K, Mahmood R, Balasubramanian, R, Food waste-to-energy conversion technologies: Current status and future directions, Waste Management, Vol. 38, 2015, pp. 399-408.

22. Manfredi S, Cristobal J, de Matos C.T, Giavini M, Vasta A, Sala S, Tuomisto H, Improving Sustainability and Circularity of European Food Waste Management with a Life Cycle Approach, JRC technical report, 2015.

23. Laurent A, Bakas I, Clavreul J, Bernstad A, Niero M, Gentil E, Christensen T.H, Review of LCA studies of solid waste management systems-Part I: Lessons learned and perspecties, Waste Management, Vol. 34, No. 3, 2014, pp. 573-588.

24. Secchi M, Castellani V, Collina E, Mirabella N, Sala S, Assessing eco-innovations in green chemistry: Life Cycle Assessment (LCA) of a cosmetic product with a bio-based ingredient, Journal of Cleaner Production, Vol. 129, 2016, pp. 269-281.

25. Cristóbal J, Torre de Matos C, Aurambout J.P, Manfredi S, Kavalov B, Environmental sustainability assessment of bioeconomy value chains, Biomass and Bioenergy, 89, 2016, 159-171.

26. Corrado S, Ardente F, Sala S, Saouter E, Modelling of food loss within life cycle assessment: from current practice towards a systematisation, Journal of Cleaner Production, Vol. 140, 2017, pp. 847-859.

27. Saraiva A.B, System boundary setting in life cycle assessment of biorefineries: a review, International Journal of Environmental Science and Technology, Vol. 14, No. 2, 2017, pp. 435-452.

28. Bernstad A.K, Cánovas A, Valle R, Consideration of food wastage along the supply chain in lifecycle assessments: A mini-review based on the case of tomatoes, Waste Management \& Research, Vol. 35, No. 1, 2017, pp. 29-39.

29. Crenna E, Sozzo S, Sala S, Natural biotic resources: towards an impact assessment framework for sustainable supply chain management, Journal of Cleaner Production, Vol. 172, 2017, pp. 3669-3684.

Open Access This chapter is licensed under the terms of the Creative Commons Attribution 4.0 International License (http://creativecommons.org/licenses/by/4.0/), which permits use, sharing, adaptation, distribution and reproduction in any medium or format, as long as you give appropriate credit to the original author(s) and the source, provide a link to the Creative Commons license and indicate if changes were made.

The images or other third party material in this chapter are included in the chapter's Creative Commons license, unless indicated otherwise in a credit line to the material. If material is not included in the chapter's Creative Commons license and your intended use is not permitted by statutory regulation or exceeds the permitted use, you will need to obtain permission directly from the copyright holder.

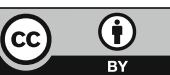

